\title{
The Sports Humanistic Spirit which the Culture of College Basketball Reflects
}

\author{
Qiuyan LI, Jian LIU* \\ Wuhan Textile University, P.R. China, 430073
}

\begin{abstract}
Basketball is very popular among students in schools, it is beneficial to the growth of the students' body, and enhance physical fitness, health promotion. Basketball culture has become a special cultural phenomenon in college. It takes students as the main body, universities as time and space, reflects students ' unique ideas, values and norms of behavior. This article based study, found that the sports humanistic spirit which college basketball culture reflects has an active role in college students ' physical, mental, ideals, morality, knowledge and personality.
\end{abstract}

KEYWORD: College; Basketball culture; Sports humanistic spirit

\section{OBJECTIVE}

In our country, basketball is very popular among students in college. It is not only a sport, but also an art and a culture. In recent years, with intercollegiate and school within various large basketball game activities carried out, and the spread of news media, with the understanding of basketball knowledge and worship of basketball stars, makes senior management sector of colleges fully aware the important of role of basketball culture in training people of full development and have seriously treated college basketball culture construction pendulum in a important of location. Then organize basketball festival, week basketball games, basketball tournament, basketball knowledge, bulletin boards, foil to create a basketball culture. These initiatives reflect effect on modern college basketball culture, and demonstrated necessity basketball culture on students ' sports humanistic spirit in university status.

\section{RESULTS AND ANALYSIS}

\subsection{Definition of the Concept}

\subsubsection{College basketball culture}

Culture of college basketball is basketball culture on University campuses breeding, nurturing and development of a cultural phenomenon. College basketball culture, refers to teachers and students at the University campus to watch basketball and engage in common during construction of campus environment and spiritual culture inheritance, innovation promotion, facilitation, basketball is the sum total of the knowledge, skills, practices and systems, is a specific culture. College basketball culture is an integral part of the basketball culture, with students as the main body, and universities as time and space, reflecting students ' unique ideas, values and norms of behavior of a culture. Mainly involve objects for contemporary college students, including students on basketball awareness and their sense of basketball and college basketball system. Major college basketball as a students ' humanistic spirit education in an important way, college basketball throughout the basketball plays a more and more important role in the system, as an important part of basketball culture, college basketball culture construction of good or bad will have a direct impact on Chinese basketball culture construction of the birth and development of basketball, has always been with the campus's development closely.

College basketball culture is the integration of campus culture and the culture of basketball, rich in its profound connotation and denotation. This article think: Real connotation of college basketball culture is basketball movement participants to campus for main space, in basketball movement in the combines pursuiting movement and humanities spirit, has health of body and sports moral, formed harmony of social value concept, reached body, spirit, ideal, moral, knowledge and personality, full of coordination unified, in this process in the formed of material wealth and spiritual of sum. 


\subsubsection{Sports humanistic spirit}

Sports Humanities spirit is stressed humanities value of sports, is refers to people active performance sports on human survival of meaning and value, is a attitude of treats right self, others, natural and society through sports, is the most fundamental of spirit orientation of human sports culture, reflected with people pursuiting on real, good and beauty, its purposes is improving sports quality and upgrade spirit realm.

Sports humanities spirit reflected in stressed individual life and respect individual of exists, it always to individual of " people " for core, maintenance people of dignity and noble, care life and health, respect people of personality needs and select, through sports activities way, fully promoting people physical and mental and spirit of health and happy, and as to promoting people full and harmony of development. Sports humanities spirit also reflected in stressed training has sense of social members, that " by self care to contact others, put with emotional from family, and school, and community expanded to society, and nation, and world "[1], so sports humanities spirit of connotation can determines for on people basic survival and development of care; on human itself health care; Optimize people's way of life and of human nature through sport development and pursuit. [2]

\subsection{Basketball sports humanistic spirit embodied in cultural content}

A. The fitness value of basketball culture

B. The health value of basketball culture

C. The aesthetic value of basketball culture

D. The charm value of basketball culture

E. The fun value of basketball culture

F. The moral value of basketball culture

\subsection{In the role of sports humanistic spirit in constructing basketball culture}

1. Retarded guide Basketball can improve students' intellectual growth. It can improve the brain's physical structure and function and all-round development of powers of observation, induced by enlightened imagination, help improve thinking ability, for the intellectual development and create favorable physiological and environmental conditions [3]. College Sports reflect the humanistic spirit is the key to developing people's emotions, sense of responsibility and values, namely life-value. How to understand the value of life, determines the way of life and people's attitude towards life, in particular learning and employment pressures, reduced ability to adapt to the society, more personality needed.
2. Education Basketball can correct outlook of life, outlook of world and values, love his country and loyalty to the people and the national spirit of constantly striving. Develop the students psychological qualities. In the course of health, will also have a positive impact on students ' psychology. By basketball it can adjust and improve the student in the day-to-day life of intense, erase negative emotions such as anxiety, insecurity, and brings entertainment and joy. Win without pride and lose with grace in the game's spirit to cultivate students ' indomitable enterprising spirit of excellent psychological quality through experience of respect for teachers, respect for opponents and referees can develop good character and personality of students.

3. Entertainment Stress physical and mental pleasure, soothe bad feelings were one of the reason why students choose and enjoy the basketball culture. Basketball culture dissemination to a large extent, met the audience of college students relieve stress and psychological needs for regulating emotions. College students in the campus basketball culture environment, experience of basketball culture transmission information, while him in stressful lives, resolve to face the various professional examinations, and job stress and anxiety. By basketball recreational and cultural activities to meet the desires, mental relaxation, to have fun, release pressure and divert attention, forget their troubles, relieve anxiety, and purify the mind, more college students participate in basketball to show themselves in the cultural activities, develop their own potential, get physical and mental pleasure and satisfaction.

4. Enrich emotional functions College physical education to provide students with a wide range of emotional experience, complied with the various requirements of modern emotion ${ }^{[4]}$ and emotions is one of the factors of human life, it comes from the family, group and community, is an important factor in supporting people to meet the challenges and overcome difficulties. Basketball friendship can develop students ' good emotions, establish good interpersonal relationships. Basketball teaching of content, and organization and the exercise process gives has students success and failed, and honors and shame, and competition and concession, emotional experience, enhanced students strongly of social sense and can training students lawabiding of consciousness, training justice, and fair of competition consciousness and civilization style makes they feel complex emotion constantly growth and perfect in various situation, for they shaped has optimistic cheerful, and active enterprising and peace face challenge of sports humanities spirit. 
5. Coagulation "To prosper and win glory for the country" has been floated from sports to social language, forming a strong patriotic spirit. Basketball is a group activity, participating in the sport, and a party for the interests of the collective game, will make them cohesive, it needs common ways of thinking, values, habits, behavior and other factors to achieve. Through basketball games can bring strong collective sense of responsibility and team spirit, requires not only five members of the team on the field to work together to mutual defense and creating offensive opportunities, and more need players, coaches, spectators, fans and other support. Through mutual exchange and communication, they are mostly positive, expressing solidarity and fair play of sports humanistic spirit, but this will enhance the cohesion of the campus. This feature of basketball culture is prominent.

\subsection{Basketball culture reflects characteristics of sports humanistic spirit of college students}

Community spirit - the spirit of collectivism is a great power, it is the spiritual pillar of common ideals and goals. Firstly Basketball is a collective project, which necessitates collaboration between people and people. Collaboration between man and nature, and social interaction, it reflects the strength of an individual solution to the collective and play a greater role.

Teamwork - Basketball is a sport that places great emphasis on teamwork among college students and tactics of basketball is the embodiment of team spirit. From the foundation to respond to the tactics of the team, each of the participants, through passing and cutting, helmeted, shield, basic offensive tactics, such as bursting, defensive tactics such as flanking finish tasks, win the game. Basketball team spirit for college students learn to cooperate with very significant.

Competition and cooperation - Human and social only can faster development in the competition, can only survive in collaboration. In the sport of basketball, in order to reflect the value of the individual, there is fierce competition between peers and opponents, and in order to achieve a collective victory, peer to close coordination and concerted action in order to achieve final victory. This universal communication, cooperation and understanding of social significance.

Sense of justice and responsibility - Basketball is carried out under strict rules and systems of healthy and civilized sport, teaching students to comply with the rules and regulations, to develop habits that follow the rules and allow the situation to get to know the problem according to the rules, tell right from wrong, not the enteric, not opportunistic, respecting the truth, promote justice, training students to hate, take a clear-cut position of spirit.

Tenacious of wills quality - Basketball movements bear much movement load, pay big physical and capacity, in movement in the will appeared fatigue sense and pain sense phenomenon, this needs students have strong wills overcome in hard of environment and movement in the elimination fear bitter, and timid, and cowardly and hesitant, bad quality, in game in the training valor tenacious, and struggle enterprising, race upstream of wills quality, has flexible wit and firmly completed task of target and determination.

Spirit of frustration - If you want to win, first of all is to overcome his psychological, ideological and temperamental weaknesses with positive attitudes. Students can understand life through basketball game he met adversity is inevitable, see if you can withstand the test. If you are able to accept setbacks, believes the future can have confidence across adversity and ultimately successful.

Innovation - An important feature of basketball is to encourage and require continuous innovation, only innovation to be invincible. Application of basic tactics of basketball is a learning process of initiative, creativity, by using the basic tactics of basketball can train students to use their brains, innovation, and imagination that provides space for training innovation consciousness.

The spirit of obey - Basketball has its own specific rules, and only within the scope permitted by the rules can showcase their skills and personality, if you exceed these rules, you will be given the appropriate punishment: being booked, his opponent kicks or service, and even appearances may be fined. These reflected on the lives of college students is to make students aware of the community or the school does have its freedom, but there is no absolute freedom, if beyond the scope provided for in national laws and rules, they will be punished by the State and school.

Responsibility - In the course of participating in basketball, regardless of team or your own full responsibility, will do their best to fight on the field, due diligence, and never give up. Through basketball, college students learn to take responsibility, to fulfil their obligations and exercise their rights. Let students know only those who will have the courage to take responsibility, with strong sense of responsibility, can be given a bigger role, qualify for the greater honor.

\section{CONCLUSION}

1. When students participate in basketball, their ideological and moral awareness manifested by a process in basketball, reflecting their campaign ethics information gained in daily basketball. 
Generally speaking, students participate in basketball, showed throughout the campaign, to reflect its sports humanistic spirit in everyday life, learning, and behavior.

2. College basketball culture plays an active role in promoting college students ' physical and mental and behavioral effects, basketball culture's influence on sports humanistic spirit and a positive attitude is the most direct and most deep. This article considers basketball culture on college students ' sports humanistic spirit in the shape of better than other items, by our students love it, huge audience, acceptability of deep and broad prospects for development

3. Basketball culture has become the focal point of campus culture development, better basketball culture reflection of sports humanistic spirit. And hoped that all colleges and universities on policy, funding, material, facilities, campus basketball culture must be based on conditions such as protection, toured the campus basketball culture, so that students can feel influence of basketball culture, the basketball culture in colleges and universities can become more prosperous.

\section{ACKNOWLEDGEMENT}

Foundation Project: This paper is a periodical result of humanities and social science research instructional project approved by The Education Department of Hubei Province, "the influence of basketball culture on the human spirit of College Students' Sports" (project number:2011jyte278).

\section{REFERENCES}

[1] Hu Xiaoming. Restricted view of Western humanism physical education sports and science 2001, (1): 5- 13

[2] Tong Zhaogang, and Sun Linlin, and Zhou Ning. Humanism physical education-physical interpretation of culture. Beijing : China Customs press , 2002:335-356

[3] Wu Hengxing, and Shen Huaisong. Discussion on the new concept of basketball College basketball culture construction. Journal of Guangzhou Institute of physical education , 2005, 25 (5): 82-84

[4] Weeks equal. Study on the education model of constructing sports humanistic spirit in colleges and universities. Journal of Wuhan Institute of physical education, 2005, 12, 21-22. 